\title{
Analysis of ceramic membrane fouling behavior and cleaning technology
}

\author{
Xinyi Zuo ${ }^{1}$, Shoubin Zhang, ${ }^{1, *}$, Guoqiang $\mathrm{Ma}^{1}$, Ying $\mathrm{Lv}^{1}$, and Peng $\mathrm{Li}^{1}$ \\ ${ }^{1}$ School of Civil Engineering \& Architecture, University of Jinan, NO.336, Nanxinzhuang West Road., Jinan 250022, P.R.China
}

\begin{abstract}
In this paper, while ceramic membrane fouling and its causes were introduced, the calculation of ceramic membrane fouling resistance, membrane fouling analysis methods and several common ceramic membrane cleaning techniques were summarized. In this process, some factors affecting the cleaning effect were also analyzed by enumerating cases, and the future development of ceramic membrane was prospected.
\end{abstract}

\section{Introduction}

Compared with traditional polymer membranes, ceramic membranes have the advantages of high surface hydrophilicity, good mechanical, physical and chemical stability, and uniform pore size distribution, therefore they are more and more widely used in wastewater treatment. At present, the initial capital cost of ceramic membranes is relatively high, and the price of commercial ceramic membrane modules is still 2 to 4 times that of similar polymer products ${ }^{[1]}$, but the ceramic membrane has a good ability to match various treatment conditions and its service life is expected to be 20 years, while the service life of polymer membrane is 7-10 years $^{[2]}$. Therefore, compared with polymer membrane, ceramic membrane has the long-term low-cost property.

However, in ceramic membrane separation technology, even under suitable operating conditions, membrane fouling will inevitably occur after long-term operation. After the membrane is contaminated, the membrane flux will decline and the filtration performance of the membrane will decrease, which will affect the life and use of the membrane. Membrane fouling is a major problem during ceramic membrane application and operation, which is mainly caused by adsorption and deposition of certain components in the filtrate on the membrane surface or in the membrane pores. Biological macromolecules with a molecular weight greater than $10 \mathrm{kDa}$ are easily trapped by the ceramic membrane. Therefore, the deposits on the membrane surface are mainly macromolecular substances such as proteins, polysaccharides, humic acid, etc., while the membrane pores are mainly blocked by small molecular pollutants ${ }^{[1]}$. In addition, it is possible that there are bacteria growing on the membrane surface or in the membrane pores, which reduces the membrane flux and causes membrane fouling. Therefore, in order to recover membrane flux, prolong the service life of the membrane and ensure the filtration performance of the ceramic membrane, the fouling behavior of the membrane must be studied, and certain measures must be taken to clean the membrane fouling, which trapped on the membrane surface or blocked in the membrane pores. This paper reviews the calculation of ceramic membrane fouling resistance, approaches of membrane fouling analysis, methods of characterization analysis, and several common ceramic membrane cleaning techniques.

\section{Analysis of fouling behavior of ceramic membrane}

\subsection{Calculation of fouling resistance}

The determination of the composition of membrane fouling resistance is helpful to analyze the influencing factors of membrane fouling, measure membranes' permeation and separation efficiency and the operation stability of membrane system, and the membrane fouling resistance is often used to represent membrane resistance of the filtrate and the degree of membrane fouling. These all provide a theoretical basis for optimizing membrane cleaning methods.

Darcy's law is used to calculate the fouling resistance

$$
J=\frac{\Delta P}{\mu R_{\mathrm{t}}}
$$

Where $\mathrm{J}$ represents the membrane permeation flux $\left(\mathrm{L} \cdot \mathrm{m}^{-2} \cdot \mathrm{h}^{-1}\right), \Delta \mathrm{P}$ is the transmembrane pressure difference ( $\mathrm{Pa}, \mathrm{TMP}), \mu$ is the osmotic viscosity $(\mathrm{PA} \cdot \mathrm{s})$, and $\mathrm{R}_{\mathrm{t}}$ is the total fouling resistance $\left(\mathrm{m}^{-1}\right)$.

In view of the universality of membrane fouling characteristics and the particularity of the experimental system, in addition to the inherent resistance of the membrane itself, the traditional resistance may also be caused by, for example, concentration polarization resistance, gel layer resistance, adsorption, precipitation

\footnotetext{
* Corresponding author: cea_zhangsb@ujn.edu.cn
} 
and membrane pore blockage. Of course, the resistance of the membrane itself is related to many factors, such as the tightness and looseness of the membrane, etc ${ }^{[3]}$.

In order to quantify and specify the membrane fouling in the membrane filtration process, the resistance can also be reclassified according to actual experimental requirements, such as clean membrane resistance, reversible fouling resistance and irreversible fouling resistance. or it can be divided into hydraulic reversible fouling resistance, hydraulic irreversible fouling resistance, chemical irreversible fouling resistance, chemical irreversible fouling resistance, and so on.

\subsection{Analysis methods of ceramic membrane fouling}

According to different experimental purposes and needs, the total organic carbon (TOC) and dissolved organic carbon (DOC) should be measured, and the unified membrane fouling index (UMFI), carbon mass balance method, particle size analyzer, potentiometer and other experimental devices or methods are used to characterize and analyze the membrane fouling behavior. The membrane surface, fouling layer and cleaning solution are characterized by means of infrared spectrum analysis, scanning electron microscope, energy spectrum analysis, atomic force microscope analysis, contact angle and so on. Some scholars also use surface-enhanced Raman spectroscopy (SERS) technology to analyze biological fouling and chemical changes in the cleaning process layer by layer, which can deeply understand the composition and dynamic changes of biofouling ${ }^{[4]}$. These data and analysis results are helpful to understand the specific behavior of membrane fouling, so as to better select the appropriate cleaning agents and effective cleaning schemes.

\section{Ceramic membrane leaning technology}

Once the solution comes into contact with the ceramic membrane, the components of the two will interact with each others by physical, chemical, and possibly biological reaction, causing some components in the solution to adsorb and deposit, meanwhile membrane fouling begins. Therefore, according to the above statement, membrane fouling is unavoidable, and the ceramic membrane must be cleaned regularly.

\subsection{Physical cleaning}

The common physical washing methods for ceramic membranes include back pressure cleaning, negative pressure cleaning, low pressure and high flow rate cleaning, mechanical scraping.

(1) Backwash method. By applying pressure on one side of the permeating liquid of the ceramic membrane, the permeating liquid will be made to pass through the ceramic membrane in the opposite direction. On the one hand, this method can wash away the contaminants blocked in the pores of the ceramic membrane, and on the other hand, it also has a certain washing effect on the adhesion layer which is on the liquid side of surface of the ceramic membrane.

(2) Negative pressure cleaning. It is similar to backwash, but it requires vacuum suction operation to create negative pressure on the functional surface side of the membrane, thereby achieving the effect of cleaning the contaminants inside and outside the membrane.

(3) Low pressure and high flow rate cleaning. Increase the velocity of the membrane surface as much as possible under a lower operating pressure, so that the probability of solute molecules staying on the membrane surface is reduced.

(4) Mechanical scraping. This method requires media such as soft foam balls and sponge balls to clean the inner surface of the membrane. Water pressure is used to clean the membrane several times for removing impurities with sponge balls, etc. At the same time, this method is also suitable for cleaning membranes, which is contaminated with organic glue as the main component.

Hyemin Lee et al. ${ }^{[5]}$ used sodium alginate solution as a representative of polysaccharide in wastewater, treated by fluidizing non-adsorbed plastic scouring media on flat-tubular ceramic membrane, and the membrane fouling was studied experimentally. In the case of with or without scouring medium, various factors such as membrane flux, $\mathrm{pH}$ and ionic strength, the influence of SA pollution on the membrane and the effect of mechanical scouring in the two cases were compared separately. The degree of membrane fouling and the change of SA particle size were analyzed in detail through experimental measurement and resistance calculation. From the whole experiment process, it could be concluded that the filter cake layer was removed by the fluidization of the scouring medium on the ceramic membrane through mechanical scouring. This method was very effective in reducing the pollution of sodium alginate.

\subsection{Chemical cleaning}

Generally, after physical cleaning, a large part of the membrane pores is still blocked by pollutants, which shows that physical cleaning can only remove a small part of the pollutants on the membrane surface and pores. At this time, chemical cleaning is needed to clean the membrane more thoroughly to restore the membrane flux.

The first step in chemical cleaning is to find a suitable material as a cleaning agent. This depends on the feed composition and the precipitated layer on the membrane surface, and the trial-and-error approach is used in most cases ${ }^{[6]}$. The cleaning agent must be able to dissolve most of the precipitated material and remove them from the surface of the membrane without causing surface damage. The seriously fouled membrane can also be cleaned alternately with acid, alkali, and oxidant, while sodium hypochlorite and surfactant can be added. The commonly used cleaning agents include a variety of chemicals, including acids $\left(\mathrm{HCl}, \mathrm{HNO}_{3}\right.$ and $\left.\mathrm{H}_{2} \mathrm{SO}_{4}\right)$, 
alkali (NaOH), chelating agent (EDTA), surfactant (SDS) and their combinations. The details of the commonly used cleaning agents are as follows.

Table 1. Commonly used cleaning agents.

\begin{tabular}{|c|c|c|}
\hline $\begin{array}{c}\text { Types of } \\
\text { cleaning agents }\end{array}$ & $\begin{array}{c}\text { Specific main } \\
\text { pharmaceutical } \\
\text { types }\end{array}$ & Application \\
\hline \multirow{2}{*}{ acids } & $\begin{array}{c}\text { Strong acid: HCL, } \\
\qquad \mathrm{HNO}_{3}\end{array}$ & $\begin{array}{c}\text { Adjust } \mathrm{pH} \text { value, } \\
\text { Dissolve organic } \\
\text { precipitate }\end{array}$ \\
\hline & $\begin{array}{c}\text { Weak acid: } \mathrm{H}_{3} \mathrm{PO}_{4} \\
\text { Citric acid }\end{array}$ & $\begin{array}{c}\text { Acidify the } \\
\text { hydrolysate of } \\
\text { macromolecules }\end{array}$ \\
\hline \multirow[t]{2}{*}{ alkalis } & $\begin{array}{l}\text { Strong alkali: } \\
\mathrm{NaOH}, \mathrm{KOH}\end{array}$ & $\begin{array}{l}\text { Adjust } \mathrm{pH} \text { value, } \\
\text { Change the surface } \\
\text { charge }\end{array}$ \\
\hline & $\begin{array}{c}\text { Weak alkali: } \\
\mathrm{Na}_{2} \mathrm{CO}_{3}\end{array}$ & $\begin{array}{c}\text { Hydrolyse protein } \\
\text { hydrolysis }\end{array}$ \\
\hline $\begin{array}{l}\text { Oxidizing } \\
\text { agents }\end{array}$ & $\mathrm{NaClO}: \mathrm{H}_{2} \mathrm{O}_{2}$ & $\begin{array}{c}\text { Oxidize organic } \\
\text { matter, Disinfect and } \\
\text { sterilize }\end{array}$ \\
\hline \multirow{2}{*}{ surfactants } & Anion: SDS & \multirow{2}{*}{$\begin{array}{c}\text { Disperse/suspend } \\
\text { sediments }\end{array}$} \\
\hline & Cation: CATB & \\
\hline chelating agents & EDTA & $\begin{array}{c}\text { Control metal ion } \\
\text { catalytic } \\
\text { decomposition }\end{array}$ \\
\hline
\end{tabular}

MohammadT.Alresheedi et al. ${ }^{[7]}$ compared the effects of three chemical cleaning agents, $\mathrm{NaClO}, \mathrm{NaOH}$, and $\mathrm{O}_{3}$, on the removal rate of calcium alginate and humic acid under different $\mathrm{pH}$ and combinations. The results showed that the removal rate of humic acid and calcium alginate by tubular ceramic UF membrane with $\mathrm{O}_{3}$ for 1 hour was higher than that of $\mathrm{NaOCl}$ or $\mathrm{NaOH}$ alone. The cleaning effect of $\mathrm{O}_{3}$ - $\mathrm{CIP}$ (clean in place) is the same as that of $\mathrm{NaOH} / \mathrm{NaOCl}$ or $\mathrm{NaOCl}+\mathrm{NaOH}-\mathrm{CIP}$ for 4 hours. Considering the time, economy and other factors, the combination of $\mathrm{O}_{3}$-CIP and ceramic membrane is a more effective and economical cleaning choice.

However, in the chemical cleaning process, there are problems such as low mass transfer rate of reaction components, large amount of cleaning agents, destruction of membrane structure by cleaning agents, especially oxidants, such as the impact of DOM produced by ozone cleaning membrane on membrane fouling, etc. ${ }^{[1]}$, so the selected materials should have the characteristics of chemical stability, safety, low cost and easy removing by water, and the parameters affecting mass transfer and chemical reaction should be taken into account. Such as temperature, $\mathrm{pH}$, dosage concentration, cleaning time, cleaning sequence and hydrodynamic conditions, these factors will affect the cleaning efficiency respectively or comprehensively to prevent irreversible damage of the membrane.

Because temperature is an important factor to control cleaning efficiency in ceramic membrane cleaning, many scholars have studied it deeply. M.C.Almecija et al. ${ }^{[8]}$ experimentally evaluated the effect of corrosive surfactant solution (most commonly used in protein cleaning) on $300 \mathrm{kDa}$ tubular ceramic membrane at three different cleaning temperatures $\left(30^{\circ} \mathrm{C}, 50^{\circ} \mathrm{C}\right.$ and $\left.60{ }^{\circ} \mathrm{C}\right)$ in order to study the effect of cleaning temperature on the permeability of ceramic membrane. They found that the cleaning temperature of $50{ }^{\circ} \mathrm{C}$ was the best. After each operation cycle at this temperature, the permeability of the ceramic membrane returns to the initial value, and the yield of protein separation was higher at this temperature. When the temperature was higher at $60^{\circ} \mathrm{C}$, the membrane hole corrosion occurred.

AliasgharGhadimkhani et al. ${ }^{[9]}$ studied the combination system of flat asymmetric ceramic membranes and air nanobubble (NBs) to clean ceramic membranes which used humic acid as an organic pollutant to simulate the organic fouling process on the surface of the membrane. After the experiment was run for more than 6 hours, humic acid was significantly deposited on the surface of the ceramic membrane, resulting in almost zero permeate flux. After the introduction of air NBs, $-\mathrm{OH}$ free radicals combined with organic matter to decompose the organic matter into small fragments to clean the whole membrane, and the flux increased significantly from zero to the initial clean flux.

\subsection{Other cleaning methods}

\subsubsection{Electric cleaning}

Electric cleaning method is to put the fouled membrane in the electric field and let the charged particles in the pollutants move with the electric field. When the ceramic membrane is filtering, the corresponding electric field is implemented with the help of time and space to make the particles on the surface and its vicinity of the membrane move in the direction of the electric field, and then remove the charged pollutants deposited on the membrane surface.

ZijunDong et al. ${ }^{[10]}$ found that the use of a small electric field would affect the content and composition of the organic matter in the supernatant of the ceramic membrane reactor and alleviate the fouling. Moreover, the formed membrane fouling layer was easier to be cleaned by simple backwashing separation.

\subsubsection{Ultrasonic cleaning}

Ultrasonic cleaning technology is the use of cavitation, acceleration and direct flow effects of ultrasonic waves in the liquid to directly and indirectly affect the liquid and dirt, making the dirt layer dispersed, emulsified, and peeled, therefore the cleaning is done.

Due to the fouling caused by the accumulation of inherent substances on the membrane surface in the process of membrane filtration, FabianReuter et al. ${ }^{[11]}$ found that ultrasound could be used to prevent fouling and clean the membrane. At the frequency of $130 \mathrm{kHz}$, the ceramic membrane could be effectively cleaned at medium driving power.

\subsubsection{Combined cleaning}


Generally speaking, ceramic membrane fouling is caused by many kinds of fouling, so a single cleaning method can't achieve the ideal cleaning effect. Multiple cleaning methods and chemical agent combinations can be used to clean in the most suitable order. Combined methods have a synergistic effect, and the cleaning effect is better than that of a single conventional cleaning method.

When it comes to combined cleaning, it is very important to find a suitable cleaning scheme. KhaledIbnAbdulHamid et al. ${ }^{[12]}$ studied the effect of ozone pretreatment $\left(\mathrm{O}_{3}\right)$ and biological activated carbon (BAC) filtration pretreatment on ceramic microfiltration (CMF) treatment of secondary effluent (SE). They found that the addition of biological activated carbon stage $\left(\mathrm{O}_{3}\right.$ BAC-CMF) between ozone pretreatment and ceramic microfiltration was detrimental to the cleaning effect. The reason was that $\mathrm{O}_{3}$ had a chemical oxidation effect on the biofilm and adsorption components of biological activated carbon, which could cause fouling.

Because the ceramic membrane has good physical and chemical stability, KatsukiKimura et al. ${ }^{[13]}$ used the circulation of granular materials (cylindrical polyurethane) in the tank and frequent chemically enhanced backwash (CEB) to enhance the physical cleaning and chemical cleaning of MBR. It was found that when the CEB strength was high, even if the granular material was used, the formation of the transparent gel layer on the surface of the film could not be ideally controlled, but when the strength of CEB was reduced to a certain extent, MBR could run stably for a long time under high membrane flux with the help of intensive mechanical cleaning. This method of mechanical scouring combined with $\mathrm{CEB}$ has been studied by many scholars. The use of granular materials for cleaning was so effective that the complete removal of cake layer / gel layer can be observed.

S.Muthukumaran et al. ${ }^{[14]}$ used surfactants combined with ultrasonic irradiation to clean the ceramic membrane fouling caused by milk wastewater, and the effect of combined cleaning was better than that of any cleaning process alone. And the surfactants can properly optimize the cleaning effect of ultrasonic method, and the combination of these two methods can increase the flux more obviously.

In addition, compared with polymer membrane, ceramic membrane has more advantages in hydraulic cleaning, that is to say, the effect of hydraulic washing on ceramic membrane fouling is much better than that of polymer membrane fouling ${ }^{[2]}$. Therefore, in these chemical and electric field cleaning processes, it is often combined with physical cleaning to achieve better cleaning effect and maximize the recovery of membrane flux, for example, under high-speed and low-pressure operating conditions, the backwash performs well.

\section{Conclusion}

Ceramic membrane separation as one of the important development directions of membrane separation technology, the most important and urgent problem to be solved is membrane fouling. In the process of research, it is necessary to make a comprehensive diagnosis of membrane fouling under different use conditions, at the same time, the diagnosis and analysis could be combined with cleaning technology to increase the flux of ceramic membrane, optimize the membrane separation performance and reduce the fouling as much as possible. In order to realize the large-scale industrialization of ceramic membrane and apply ceramic membrane into more fields, it is necessary to continue in-depth research on ceramic membrane fouling and the practical application of cleaning technologies in various fields in the future.

\section{References}

1. H. Sun, H. Liu, S. Wang, F. Cheng, Y. Liu. Water Res, 146, 328-336(2018)

2. M.T. Alresheedi, B. Barbeau, O.D. Basu. Sep. Purif. Technol. 209, 452-460(2019)

3. M. Racar, D. Dolar, K. Košutić. Sep. Purif. Technol. 188, 140-146(2017)

4. L. Cui, P. Chen, B. Zhang, D. Zhang, J. Li, F.L. Martin, K. Zhang. Water Res, 87, 282-291(2015)

5. H. Lee, R. Ahmad, J. Kim. Bioresour. Technol. 302, 122813(2020)

6. S.S. Madaeni, S. Samieirad. Desalination, 257, 8086(2010)

7.M.T. Alresheedi, O.D. Basu, B. Barbeau. Chemosphere, 226, 668-677(2019)

8. M.C. Almecija, A. Martinez-Ferez, A. Guadix, M.P. Paez, E.M. Guadix. Desalination, 245, 708713(2009)

9. A. Ghadimkhani, W. Zhang, T. Marhaba. Chemosphere, 146, 379-384(2016)

10. Z. Dong, W. Shang, W. Dong, L. Zhao, M. Li, R. Wang, F. Sun. Bioresour. Technol. 270, 113119(2018)

11. F. Reuter, S. Lauterborn, R. Mettin, W. Lauterborn. Ultrason Sonochem, 37, 542-560(2017)

12. K. Ibn Abdul Hamid, P. Sanciolo, S. Gray, M. Duke, S. Muthukumaran. Water Res, 126, 308-318(2017)

13. K. Kimura, H. Uchida. Water Res, 150, 21-28(2019)

14. S. Muthukumaran, K. Yang, A. Seuren, S. Kentish, M. Ashokkumar, G.W. Stevens, F. Grieser. Sep. Purif. Technol. 39, 99-107(2004) 